\title{
KONSEP TEOLOGI ISLAM DALAM PELAKSANAAN TRADISI KEUMAWEUH DAN PEUSIJUK DI KECAMATAN LABUHAN HAJI KABUPATEN ACEH SELATAN
}

\section{CONCEPT OF ISLAMIC THEOLOGY IN THE IMPLEMENTATION OF KEUMAWEUH TRADITION AND PEUSIJUK IN LABUHAN HAJI SUBDISTRICT, SOUTH ACEH REGENCY}

Fuadi $^{1}$

fuadiatjeh@gmail.com

UIN Ar-Raniry Aceh

Dian Popi Oktari ${ }^{2}$

STIT NU Sumber Agung Oku Timur

dianpopiokt@gmail.com

\begin{abstract}
ABSTRAK: Dalam konsep teologi Islam di kebudayaan masyarakat Aceh yang masih dilestarikan dan dipraktekkan salah satu adatnya adalah keumaweuh dan peusijuk. Adat ini sebagai sebuah budaya yang telah menjadi bagian dari Islam, khususnya masyarakat Islam di Aceh. Penelitian ini ingin mengungkap bagaimana keumaweuh dan peusijuk diyakini dan beroperasi menjadi sebuah kepercayaan masyarakat yang secara keagamaan hal tersebut bukan sepenuhnya murni berasal dari ajaran agama. Penelitian ini menggunakan metode content analisis. Islam memiliki konsep universalisme yang mampu menyatu dan melebur dalam berbagai peradaban dan kebudayaan, Islam menyatu dan dapat diterima oleh berbagai bangsa dan peradaban. Keumaweuh dan peusijuk diyakini oleh masyarakat Aceh sebagai salah satu ritual yang dikaitkan dengan kepercayaan terhadap agama, karena syarat dengan nilai-nilai agama, yang mesti dijalankan. Hal tersebut dapat dilihat dari 3 (tiga) unsur, yaitu pertama; Pelaku Peusijuek, biasanya dilakukan oleh para tengku (ustadz) yang paham agama. Kedua, momen keumaweuh dan peusijuk. Ketiga, doa yang dibacakan adalah doa yang ditujukan kepada Allah SWT, dengan menggunakan doa-doa yang dari al-Qur'an dan Sunnah. Melihat ketiga tinjauan tersebut, dapat disimpulkan bahwa adat masyarakat Aceh keumaweuh dan peusijuk sangat syarat dengan nilai-nilai keislaman dan keyakinan terhadap nilai-nilai Islam, sehingga menjadi sebuah kepercayaan masyarakat.
\end{abstract}

Kata Kunci: Keumaweuh, Peusijuek, Adat Aceh, Islam.

ABSTRACT: In the concept of Islamic theology in acehnese culture that is still preserved and practiced one of the customs is keumaweuh and peusijuk. This custom as a culture that has become part of Islam, especially the Islamic community in Aceh. This research wants to uncover how keumaweuh and peusijuk are believed and operate into a community belief that is not entirely purely derived from religious teachings. This study uses content analysis method. Islam has a concept of universalism that is able to unite and merge in various civilizations and cultures, Islam is unified and acceptable to various nations and civilizations. Keumaweuh and peusijuk are believed by the Acehnese to be one of the rituals associated with religious beliefs, because of the conditions with religious values, which must be carried out. This can be seen from 3 (three) elements, namely the first; Peusijuek actors, usually done by tengku (ustadz) who understand religion. Second, the moment of keumaweuh and peusijuk. Third, the prayer that is recited is a prayer addressed to Allah SWT, using prayers from the Quran and Sunnah. Looking at the three reviews, it can be concluded that the indigenous people of Aceh keumaweuh and peusijuk are very conditional with Islamic values and beliefs in Islamic values, so that become a public trust.

Keywords : Keumaweuh, Peusijuek, Aceh Culture, Islamic. 


\section{A. PENDAHULUAN}

Dalam perkembangan ilmu pengetahuan yang mendorong semua aspek kehidupan dan cenderung dikaitkan dengan kajian-kajian teologis, yang bertujuan untuk ingin merefleksikan hubungan manusia dan Tuhan. Karena dalam berteologi terdapat unsurunsur "intelectus quarens fidem" (akal menyelidiki isi iman) ${ }^{1}$ yang diharapkan dapat memberikan sumbangan secara subtansial untuk Iman dan akal, Iptek dan Imtaq, dan yang bermanfaat bagi kehidupan manusia berikutnya. Kesadaran tentang kajian teologi secara tidak langsung para kalangan akademisi sangat ingin menemukan objek yang sesuai dengan objek material teologi dalam bentuk praktik kebudayaan, dikarenakan kajian teologi sering dianggap membicarakan persoalan ketuhanan, spritual, dan kemanusiaan yang bersifat mistis, tetapi seiring dengan perkembangan waktu ruang lingkup kajian teologi semakin melebar luas. ${ }^{2}$

Dalam konsep teologi, posisi agama memberikan ruang tentang sejauh mana pengaruh suatu kebudayaan atau tradisi yang bernilai dan bermoral, karena agama sangat mempengaruhi kualitas teologi dalam suatu kebudayaan atau tradisi. Tanpa aspek agama sulit bagi kebudayaan mengandung aspek teologi dan dalam kajian filsafat Islam aspek teologi dalam kebudayaan akan berujung keadaban dan moralitas. ${ }^{3}$ Kebudayaan atau tradisi terdiri atas gagasan, simbol-simbol dan nilai-nilai yang bersumber dari manusia di kala itu. Sedangkan kebudayaan agama adalah karya Allah. Dengan demikian, agama bukan bagian dari budaya dan adat pun bukan bagian dari agama. Ini tidak berarti bahwa keduannya saling terpisah, melainkan saling berhubungan erat satu sama lain.

Islam masuk ke Aceh salah satunya disebabkan melalui pendekatan budaya dan adat istiadat yang telah lama mendarah daging sebelum Islam masuk ke Aceh. ${ }^{4}$ Kemudian Aceh sampai sekarang merupakan suatu daerah yang sangat kental akan adat istiadat yang berkaitan erat dengan agama Islam, sehingga muncul filosofi dalam masyarakat Aceh yaitu "adat ngon hokom lagee dzat ngon sifet" (adat dan hukum seperti zat dan sifat). Kalimat ini menandakan bahwa teologis yang terdapat dalam hukum serta adat istiadat di Aceh sulit untuk dipisahkan dan fakta teologi seperti ini tentunya juga dimiliki nilainya

\footnotetext{
${ }^{1}$ Imam Syafi’e, “Teologi Pendidikan: Epistemologis, Ontologis, dan Aksiologis,” Ijtimaiyya 6, no. 2 (2013).

2 Jalaluddin Rakhmat, Afkar Pengantar (Bandung: Nuansa Cendikia, 2016).

${ }^{3}$ Haidar Bagir, Islam Tuhan Islam Manusia (Bandung: Mizan Pustaka, 2017).

${ }^{4}$ Taqwadin Husin, Kapita Selekta Hukum Adat Aceh dan Qanun Lembaga Wali Nanggroe (Banda Aceh: Bandar Publishing, 2013).
} 
oleh daerah-daerah lain selain Aceh. Adat Aceh dalam suatu peran dan fungsinya digambarkan sebagai “udep tan adat lagee kapai tan nahkoda” (hidup tanpa adat, semacam kapal yang tidak mempunyai nahkoda. ${ }^{5}$

Masyarakat Aceh memiliki berbagai kebiasaan yang telah menjadi tradisi atau adat yang berfungsi sebagai pedoman dalam perbuatan sehari-harinya. Kebiasaan-kebiasaan ini telah berlaku antar generasi dalam suatu masyarakat, di mana keberadaannya menjadi pedoman dalam berfikir dan bertindak di masyarakat pemangku adat tersebut. Adat budaya Aceh telah dipraktikkan oleh masyarakat secara turun temurun dan dilakukan secara berulang-ulang dalam kurun waktu yang relatif lama. Hal ini telah menjadikan kegiatan keharusan dalam lingkungan kemasyarakatan salah satunya seperti adat keumaweuh dan peusijuk. Adat keumaweuh dan peusijuk merupakan adat Aceh yang sejak dulu hingga kini sangat menonjol, bermakna, dan penting bagi masyarakat Aceh, terutama pada masyarakat Aceh di Kecamatan Labuhan Haji, Kabupaten Aceh Selatan.

Menurut pemahaman adat keumaweuh atau disebut juga dengan adat Mèe bu. Di mana kebiasaan ini terjadi dalam masa tujuh bulanan sang ibu dalam mengandung bayi pertamanya, agar diberi keselamatan bagi bayi di dalam kandungan ibu. Adat ini merupakan tanggung jawab keluarga dalam hal ini orang tua (ayah dan ibu) terhadap anak pertamanya. Tujuan utama dilakukan adat keumaweuh sebagai pernyataan bahwa janin yang dikandung oleh istri (dara barô) adalah benar-benar asli dan sah menurut syara' dan adat sebagai bagian dalam keluarga atau kerabat. Sikap pernyataan ini merupakan kebutuhan rohani atau moril sang istri dalam upaya memenuhi kebahagiaan. ${ }^{6}$

Adat peusijuk atau menepung tawar dari kata sijuek dari bahasa Aceh yang berarti dingin, kemudian ditambah awalan peu, jika di gabungkan mempunyai maksud agar sesuatu menjadi dingin, atau mendinginkan. ${ }^{7}$ Di mana kebiasaaan peusijuk ini dilakukan pada kegiatan-kegiatan tertentu dalam kehidupan masyarakat Aceh, seperti peusijuek pada upacara perkawinan, upacara tinggal di rumah baru, upacara hendak merantau, pergi/naik haji, peusijuek keureubeuen (kurban), peusijuek keberuntungan, misalnya berhasil lulus sarjana, peusijuek kendaraan baru, dan lainnya. Semua peusijuek ini bertujuan sebagai penyataan rasa syukur segala nikmat kepada Allah atas yang

\footnotetext{
${ }^{5}$ Badruzzaman Ismail, Majelis Adat Aceh Provinsi NAD (Banda Aceh: Majelis Adat Aceh (MAA), 2007).

${ }^{6}$ Syamsuddin Daud, Adat Meukawen (Banda Aceh: Majelis Adat Aceh (MAA), 2014).

${ }^{7}$ Marzuki Abubakar, "Tradisi Peusijuek dalam Masyarakat Aceh: Integritas Nilai-Nilai Agama dan Budaya,” El-Harakah 13, no. 2 (2012): 133-49.
} 
pemberian-Nya, sekaligus sebagai permohonan dan harapan untuk keberkahan dan keselamatan dalam hidup. Selain itu peusijuek juga merupakan simbol adat untuk meminta maaf kepada sesama manusia atas suatu kesalahan dan kekhilafan. ${ }^{8}$

Dalam beberapa tahun terakhir ini adat atau tradisi keumaweuh dan peusijuek sudah mulai ditinggalkan oleh beberapa kelompok masyarakat, pengaruhnya dari kalangan reformis, yang menjadikan fokus pembersihan ajaran-ajaran Islam dari sinkretisme atau konsep yang mengandung harmonisasi dan nilai-nilai budaya yang berbeda, yang diikuti oleh pelaku budaya dan sekte-sekte yang berbeda, dengan menganut dua indikator. Pertama, memurnikan agama komponen-komponennya meliputi kembali kepada teks suci, serba syariah, dan tidak taklid. Kedua, menjauhi sinkretisme, komponenkomponennya yaitu menolak untuk mengikutinya, dan tidak melakukan selamatan. Gerakan ini hanya diterima dan berkembang di perkotaan saja. Gerakan pemurnian ini belum terlalu berkembang pada masyarakat yang berada di pedesaan terutama di Kecamatan Labuhan Haji, Kabupaten Aceh Selatan.

Oleh karena itu, dari latar belakang di atas penulis hendak menguraikan nilai-nilai agama Islam yang terintegrasi dengan tradisi atau kebudayaan yang terdapat dalam adat keumaweuh dan peusijuek di Kecamatan Labuhan Haji, Kabupaten Aceh Selatan. Sebab tradisi dan kebudayaan tersebut sampai saat ini masih diterima dengan baik oleh mayoritas masyarakat Aceh Selatan secara keseluruhan dan menjadi sebuah budaya Islam dalam masyarakat setempat.

\section{B. METODE PENELITIAN}

Dalam menyusun artikel ini, penelitian ini menggunakan metode deskriptif kualitatif, pendekatan yang penulis lakukan dalam penelitian adalah dengan pendekatan lapangan (field research). Penulis menyelidiki atau mencari bukti-bukti yang muncul sehubungan dengan masalah adat keumaweuh dan peusijuk dengan cara observasi, wawancara dan dokumentasi di Kecamatan Labuhan Haji, Kabupaten Aceh Selatan. Data responden pada penelitian ini terdiri dari tokoh adat, pemuka agama dan masyarakat setempat di Kecamatan Labuhan Haji, Kabupaten Aceh Selatan.

\footnotetext{
${ }^{8}$ Badruzaman Ismail, Mesjid dan Adat Meunasah Sebagai Sumber Energi Budaya Aceh (Banda Aceh: Majelis Pendidikan Daerah, 2002).
} 


\section{HASIL DAN PEMBAHASAN}

\section{Pelaksanaan Adat Keumaweuh dan Peusijuk di Masyarakat Aceh}

\section{a. Adat Keumaweuh}

Dalam adat keumaweuh belum ada kajian secara spesifik, tetapi sebenarnya adat keumaweuh itu begitu dekat dengan tradisi tujuh bulanan yang tidak hanya ada di dalam masyarakat Aceh tapi diberbagai etnik juga ada dalam masyarakat Jawa dan sebagainya. Adat keumaweuh dipersiapkan dengan upacara keselamatan untuk si bayi dan diwujudkan dalam tradisi oleh pihak keluarga suami, datang mengunjungi dengan membawa nasi dan lauk pauk serta dilengkapi buah-buahan yang disebut Mèe bu. Masa kehamilan dalam masyarakat Aceh diabadikan dalam sebuah syair yang menggambarkan proses kehamilan itu.

"Bukon tat sayang dipo ma, Bak buleuen keu dua hana meutente,

Bak buleuen keu lheu kaleumah tanda, Bak buleuen keu peut rame ureung tanyong, Bak buleuen keu limong boh kaye gob ba, Bak buleuen keu tujoeh makanan geuba, Bak buleuen keu lapan saket lam tuleueng, Bak buleuen sikureung lahe balita",9

Dijelaskan dari syair di atas di mana urut-urutan yang akan dialami masa kehamilan seorang ibu sampai hari melahirkan. Pada bulan ketiga masa kehamilan datang dengan tanda-tanda, bulan keempat, ibu mertua diam-diam melakukan kunjungan secara tiba-tiba mengunjungi menantunya yang sedang hamil muda dengan membawa (bawaan ini disebut dengan buè cu, yang terdiri dari lauk yang sama pada waktu mengantar nasi dalam jumlah yang banyak. Pada masa kehamilan ke lima atau ketujuh, kembali lagi ibu mertua datang berkunjung dengan membawa nasi dan buah-buahan dengan pengantar yang lebih banyak. Nasi yang dibawa oleh mertua kepada menantu yang sedang hamil anak pertama dikenal dengan sebutan mèe nalle.

Dalam makna keumaweuh ada pantangan bagi wanita hal tidak boleh dilakukan oleh ibu hamil pada masa kehamilan. Pantangan tersebut apabila dilakukan akan membawa keburukan, baik kepada si calon ibu maupun sang anak, pantangan banyak yang berkembang dimasyarakat banyak dipengaruhi oleh mitos hal gaib yang ada dikalangan masyarakat. Bagi masyarakat zaman dulu, pantangan sering di hindari karena masih banyak orang tua yang paham dan percaya akan hal

\footnotetext{
${ }^{9}$ Daud, Adat Meukawen.
} 
tersebut. Namun di zaman sekarang yang sudah lebih maju, hanya sebagian orang yang masih percaya akan hal ini.

Pantangan tersebut misalnya wanita hamil tidak boleh duduk diatas tangga, kalau tidak proses kelahiran akan sulit, tidak boleh melihat kera dikhawatirkan anaknya akan mirip kera. Larangan lainnya adalah sang suami tidak boleh keluar di malam hari, karena dikhawatirkan makhluk gaib seperti burong akan ikut masuk kerumah ketika suami pulang. ${ }^{10}$ Dari hasil wawancara beberapa masyarakat wanita Kecamatan Labuhan Haji, Kabupaten Aceh Selatan, dijelakan bahwa :

"masyarakat Aceh adalah masyarakat yang sangat menjaga adatnya. Jadi dapat dikatakan adat keumaweuh ini sudah ada dari nenek moyang jaman dahulu sampai turun-temurun dan menjadi suatu kebiasaan bagi masyarakat kita pada umumnya, khususnya masyarakat di Kecamatan Labuhan Haji. Dilihat dari segi zaman dahulu upacara adat keumaweuh ini dilakukan dengan khanduri atau ritual keagamaan yang kecil-kecilan atau tidak mewahmewahan, bukan seperti sekarang yang sudah dibesar-besarkan dan dilebihlebihkan. Ini terjadi dikarenakan perubahan sosial dan seiring dengan perubahan zaman juga. Sebagian masyarakat yang tidak mampu juga ikut melakukan adat keumaweuh ini cukup dengan memberi sedekah kepada anak yatim".

Berdasarkan dari penjelasan di atas, adat keumaweuh merupakan adat yang dilaksanakan oleh masyarakat Labuhan Haji dengan penuh suka cita. Sehingga tidak jarang pada usia kehamilan tujuh bulanan ini masyarakat tidak keberatan dalam menjalaninya.

\section{b. Adat Peusijuk}

Dalam adat Peusijuk di masyarakat Aceh adalah suatu bentuk ritual keagamaan yang dilakukan dengan sebuah acara berkaitan dengan hal-hal tertentu. Selain itu acara peusijuk ini juga selalu dilakukan pada hal-hal yang penting dan dianggap sakral karena mendatangkan berbagai karamah dan keuntungan. Tradisi peusijuk biasanya dilakukan untuk memohon keselamatan dan kebahagiaan dalam hidup. Peusijuk bertujuan untuk menampakkan rasa syukur kepada Allah SWT atas keberhasilan yang diperoleh serta keselamatan yang akan dituju agar terlepas dari berbagai marabahaya.

\footnotetext{
${ }^{10}$ Meutia Farida Swasono, "Kehamilan Kelahiran Perawatan Ibu Hamil dan Bayi dalam Konteks Budaya" (Jakarta: Universitas Indonesia, 1997).
} 
Kesakralan upacara peusijuek ini diperkuat dengan terlibatnya pemuka agama yang ditekuni dalam masyarakat setempat. Hal inilah yang menyebabkan upacara peusijuek terus bertahan hingga saat ini dalam etnik Aceh terutama di masyarakat Kecamatan Labuhan Haji. Dalam sesi Wawancara salah seorang pimpinan pemuka tokoh adat mengemukakan bahwa:

"peusijuek dalam masyarakat kami sudah lama diwariskan oleh nenek-monyang dan tidak ada yang mengetahui sejak kapan dimulainya adat tersebut. Bagi kami, upacara peusijuek ini dapat mendatangkan keinginan yang diinginkan dari pelaksanaannya dan menjauhkan bala, contoh peusijuek motor baru di mana kami mengharapkan agar pemilik kendaraan tidak ditimpa musibah kecelakaan, dan jika yang dipeusijuek adalah motor untuk bekerja, maka diharapkan mendatangkan rezeki yang banyak".

Dari penjelasan diatas menunjukkan bahwa masyarakat Kecamatan Labuhan Haji Timur menganggap bahwa upacara peusijuek merupakan suatu yang sakral karena dapat mendatangkan keberkahan rezeki di masa mendatang. Hal ini dibuktikan di mana tidak hanya sekelompok masyarakat yang meyakininya melainkan hampir setiap golongan masyarakat melaksankan tradisi peusijuek tersebut. Keyakinan masyarakat Kecamatan Labuhan Haji terhadap keuntungan melakukan upacara peusijuek ini tidak hanya terdapat pada pelaku dan proses pelaksanaanya, melainkan juga dianggap mengandung filosofi untuk kebaikan masa depan bagi mereka yang dipeusijuek, seperti ungkapan berikut ini:

"setahu saya salah satu perlengkapan yang sering dan wajib ada dalam pelaksanaan peusijuek di dalam masyarakat Kecamatan ini ialah beras pulut yang dalam bahasa Aceh disebut bu leukat dalam bahasa kami setempatt. artinya beras ketan yang telah di masak. Beras ketan dalam tradisi ini harus diberikan warna kuning atau putih. Maknanya untuk mengandung zat yang pengikat, sehingga jiwa dan raga orang yang di peusijuek tetap berada dalam lingkungan keluarga dan masyarakat. Warna kuning dari beras ketan dalam tradisi peusijuek juga mengandung makna akan lambang kejayaan dan kemakmuran, sedangkan warna putih melambangkan tanda suci dan bersih. Sehingga orang yang akan di peusijuek itu dapat memberi manfaat yang lebih baik bagi orang lain dan orang yang di peusijuek itu juga selalu berada dalam suasana yang tentram untuk menuju jalan yang benar. ${ }^{11}$

Berdasarkan pernyataan di atas dijelaskan bahwa kesucian adat peusijuek dalam masyarakat Kecamatan Labuhan Haji tidak hanya terlihat pada proses pelaksanaan, pesan-pesan yang disampaikan dalam pelaksanaan dan pihak yang

${ }^{11}$ Wawancara: Jamaluddin, tuha pheut Sebrang Kecamatan Labuhan Haji, tanggal 24 Juni 2020 
terlibat dalam pelaksanaannya, melainkan juga diyakini akan kelebihan dan makna yang dari peralatan serta bahan yang digunakan.

\section{Makna Teologi Islam yang terkandung dalam Adat Keumaweuh dan Peusijuk}

Masyarakat Aceh menjadikan Islam sebagai pedoman hidup. Hukum Islam telah menjadi bagian dari mereka dengan segala kelebihan dan kekurangannya. Kemudian seluruh masyarakatnya tunduk kepada ajaran Islam dan taat serta memperhatikan fatwa ulama, Karena ulama lah yang menjadi ahli waris Nabi Muhammad saw. Penghayatan terhadap ajaran agama Islam dalam jangka waktu yang panjang telah melahirkan budaya Aceh yang tercermin dalam kehidupan adat. Adat itu lahir pada renungan ulama, kemudian dipraktikkan, dikembangkan, dan dilestarikan oleh masyarakat sampai saat ini.

Ada empat sumber utama dalam Adat Aceh yaitu Pertama, Adatullah, yaitu hukum adat yang bersumber hampir seluruhnya (mutlak) pada hukum Allah (al-Qur'an dan al-Hadis). Kedua, Adat Tunnah, yaitu adat istiadat sebagai manifestasi dari Qanun yang mengatur kehidupan masyarakat. Ketiga, Adat Muhakamah, yaitu hukum adat yang dimanifestasikan pada asas musyawarah dan mufakat. Kemudian yang keempat Adat Jahiliyah, yaitu adat istiadat dan kebiasaan-kebiasaan masyarakat yang kadangkadang tidak sesuai dengan ajaran Islam, namun masih ada sebagian yang digemari oleh masyarakat. ${ }^{12}$

Masyarakat Aceh meyakini bahwa agama dan adat pada dasarnya mengandung nilai-nilai sumber daya yang dijadikan aset untuk menggerakkan upaya pencapaian kemakmuran serta kesejahteraan. Nilai-nilai yang bersumber pada agama dan adat sangat menekankan ketekunan, kesabaran, kedisiplinan dan kesungguhan setiap kegiatan dalam kehidupan sehari-hari dalam bermartabat. Adat keumaweuh dan peusijuk juga dimaknakan oleh masyarakat sebagai bentuk rasa syukur atas limpahan nikmat yang diberikan oleh Allah SWT salah satunya dikaruniakan sibuahati dalam makna adat keumaweuh dan keberkahan rezeki di masa mendatang dalam makna peusijuk.

Tujuan lain dari adat secara umum untuk menjalinan silaturahmi antar manusia satu dengan manusia lainnya. Di sini jelas bahwa penciptaan perdamaian dan

\footnotetext{
${ }^{12}$ Ismail, Mesjid dan Adat Meunasah Sebagai Sumber Energi Budaya Aceh.
} 
silaturahmi dalam budaya Aceh ini tidak lepas dari ajaran Islam dan ini merupakan salah satu yang sudah tertanam dalam adat istiadat masyarakat Aceh, khususnya pada masyarakat Kecamatan Labuhan Haji. Ini merupakan salah satu hal yang penting yang harus dibudidayakan kembali dalam kehidupan bermasyarakat. Allah SWT berfirman di dalam Q.S. Ibrahim ayat 7 :

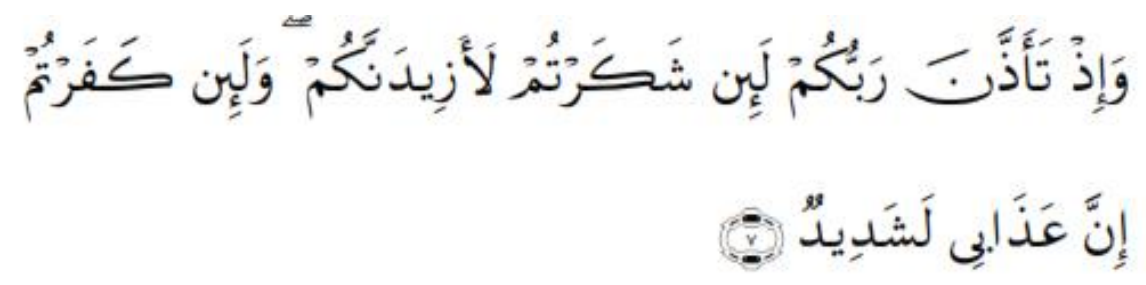

Artinya: Dan (ingatlah juga), tatkala Tuhanmu memaklumkan "Sesungguhnya jika kamu bersyukur, pasti Kami akan menambah (nikmat) kepadamu, dan jika kamu mengingkari (nikmat-Ku)", maka Sesungguhnya azab-Ku sangat pedih.

Dari Ayat diatas mengingatkan kita selalu bersyukur atas nikmat Allah berikan. Adat bukan hukum Islam, hanya melainkan bahagian dari kebiasaan masyarakat yang sudah menjadi hukum yang bernuansa keislaman. Adat ini pada mulanya bersifat kehinduan, tetapi setelah datangnya Islam maka adat ini sudah diislamisasikan dikaitkan dan dihubungkan sesuai dengan ajaran-ajaran Islam dengan tujuan memperkuat tali persaudaraan, memperdulikan atau mengasihi anak yatim dan orang miskin, serta berzikir agar selalu mengingat Allah SWT.

Allah Swt berfirman di dalam Q.S. An-Nisa' ayat 1 :

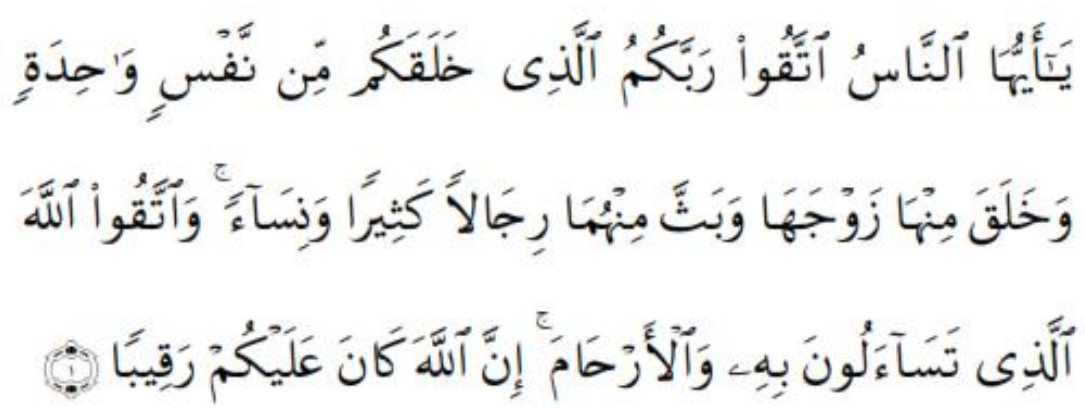

Artinya: Hai sekalian manusia, bertakwalah kepada Tuhanmu yang telah menciptakan kamu dari seorang diri, dan dari padanya Allah menciptakan isterinya; dan dari pada keduanya Allah memperkembang biakkan laki-laki dan perempuan yang banyak dan bertakwalah kepada Allah yang dengan (mempergunakan) nama-Nya kamu saling meminta satu sama lain, dan (peliharalah) hubungan silaturrahim. Sesungguhnya Allah selalu menjaga dan mengawasi kamu. 
Ayat diatas jika ditinjau dari kehidupan masyarakat Aceh dalam adat keumaweuh, pendapat para ulama tersebut memiliki dalil yang menguatkan pendapatnya, sekarang hanya bisa memilih mana yang terbaik dalam kehidupan bersosial dan bermasyarakat. Tujuan masyarakat Kecamatan Labuhan Haji melaksanakan kegiatan keumaweuh adalah tidak lain hanya untuk mendoakan keselamatan ibu bayi dan si bayi itu sendiri pada saat proses melahirkan tiba. Tujuan lain supaya tidak diasingkan di kalangan masyarakat karena tidak melaksanakan adat tersebut, karena dianggap sebagai manusia yang tidak melestarikan adat dan budaya tersebut. Karena pada dasarnya adat keumaweuh hanya untuk berinteraksi maupun bersosial kepada masyarakat lainnya.

Dalam kehidupan bermasyarakat adat peusijuk ada yang membolehkan dengan mengungkapkan dalil dari kitab kuning, berdasarkan perbuatan Rasulullah saw. Diriwayatkan bahwa Nabi Muhammad saw pernah melakukan percikan air ketika Ali dan Fatimah menikah. Riwayat lain juga dikatakan bahwa Nabi Muhammad saw pernah mendoakan cucu beliau Hasan dan Husen dengan percikan air. ${ }^{13}$

Sebagian lain juga memberikan alasan diperbolehkan karena perbuatan peusijuek tersebut intinya adalah berdoa dan tidak ada unsur sama sekali syirik dengan bahan-bahan yang digunakan dalam upacara peusijuek tersebut. Karena semua doa dan harapan yang diucapkan hanya ditujukan kepada Allah SWT. Dengan unsur bahan yang digunakan dalam adat peusijuek seperti daun-daunan, padi, beras, dan air merupakan simbol yang digunakan untuk sebuah harapan dari bentuk dan sifat dari masing-masing benda yang dipilih untuk digunakan, sehingga yang dipeusijuek mengikuti unsur dari bahan tersebut. ${ }^{14}$

Bila dilihat dari sudut pandang ajaran Islam, banyak sekali dalil-dalil agar manusia senantiasa berdoa dan meminta kepada Allah SWT. Dalam keyakinan ahlussunnah waljama'ah, manusia wajib untuk berdoa dan berusaha walaupun segalanya telah ditentukan oleh Allah SWT. Pengharapan ini selalu mendapat rahmat dan keberkahan dari Allah dilakukan dengan berdoa.

Adat keumaweuh dan peusijuk dilihat dari sisi pantangan dan tidak dipatuhi akan membawa dampak negatif bagi orang-orang yang melanggarnya. Karena itulah

\footnotetext{
${ }^{13}$ Wawancara: Abu Baka, Tengku Imum Meukek Kecamatan Labuhan Haji

14 Wawancara: Abu Ustman, Tengku Dayah Trumon Kecamatan Labuhan Haji
} 
pantangan ini sangat penting dijaga oleh masyarakat Aceh supaya dapat membawanya kepada hal positif dari pantangan itu sendiri. Pantangan ini merupakan suatu adat istiadat yang tidak tertulis dan berlaku dalam kehidupan masyarakat, sehingga sebagian besar diterima dan diakui oleh masyarakat Aceh. Tetapi masyarakat percaya bahwa pantangan tersebut dapat mendukung adat istiadat yang dilakukan masyarakat kearah yang lebih bermanfaat.

Kepercayaaa pada hal yang ghaib dalam masyarakat Aceh bukanlah dikatakan budaya, sehingga jika terdapat kepercayaan atau cara-cara yang berlaku serta sikap dan hasil kegiatan masyarakat dan ternyata bertentangan dengan Akidah Islamiyah maka hal tersebut tidak akan dianggap budaya ataupun adat Aceh yang sesungguhnya. Dengan begitu budaya atau adat merupakan simbol nilai dan konsep tentang kehidupan bermasyarakat orang Aceh.

\section{SIMPULAN}

Dari pembahasan di atas dapat disimpulkan bahwa keumaweuh dan peusijuk adalah salah satu budaya Islam yang sampai sekarang masih dilestarikan dan menjadi ritual resmi bagi masyarakat di Aceh. Walaupun sebagian berpendapat bahwa sebuah perbuatan bid'ah yang harus ditinggalkan. Keumaweuh dan peusijuek memiliki unsurunsur atau nilai-nilai agama yang menjadi ruhnya. Hal tersebut dilihat dari sisi bahwa Islam memiliki konsep universalisme yang mampu menyatu dan melebur dalam berbagai peradaban dan kebudayaan.

Seluruh prosesi pelaksanaan praktik adat keumaweuh dan peusijuk ini dilakukan semua hanya semata-mata untuk Allah SWT. Sehingga manusia selalu ingat akan nikmat dan karunia yang telah diberikan oleh Allah untuknya. Segala apapun yang manusia kerjakan harus diniatkan untuk Allah SWT. Dengan demikian hidup akan lebih tenang, damai, dan bahagia, dan yang terpenting yang putus dari kata-kata bersyukur.

\section{DAFTAR PUSTAKA}

Abubakar, Marzuki. "Tradisi Peusijuek dalam Masyarakat Aceh: Integritas Nilai-Nilai Agama dan Budaya." El-Harakah 13, no. 2 (2012): 133-49.

Bagir, Haidar. Islam Tuhan Islam Manusia. Bandung: Mizan Pustaka, 2017.

Daud, Syamsuddin. Adat Meukawen. Banda Aceh: Majelis Adat Aceh (MAA), 2014.

Husin, Taqwadin. Kapita Selekta Hukum Adat Aceh dan Qanun Lembaga Wali Nanggroe. 
YAQZHAN | Volume 07, Nomor 02, Desember 2021

Banda Aceh: Bandar Publishing, 2013.

Ismail, Badruzaman. Mesjid dan Adat Meunasah Sebagai Sumber Energi Budaya Aceh.

Banda Aceh: Majelis Pendidikan Daerah, 2002.

Ismail, Badruzzaman. Majelis Adat Aceh Provinsi NAD. Banda Aceh: Majelis Adat Aceh (MAA), 2007.

Rakhmat, Jalaluddin. Afkar Pengantar. Bandung: Nuansa Cendikia, 2016.

Swasono, Meutia Farida. "Kehamilan Kelahiran Perawatan Ibu Hamil dan Bayi dalam Konteks Budaya.” Jakarta: Universitas Indonesia, 1997.

Syafi'e, Imam. "Teologi Pendidikan: Epistemologis, Ontologis, dan Aksiologis." Ijtimaiyya 6, no. 2 (2013). 